\title{
NOTION OF PRIVATE LANGUAGE IN WITTGENSTEIN'S TRACTATUS LOGICO-PHILOSOPHICUS AND SOME CONTEMPORARY LINGUISTIC REFUTATIONS
}

\author{
Marko Kardum, Ines Skelac $\quad$ UDK 1Wittgenstein, L. \\ $81: 1$ \\ Original scientific paper \\ https://doi.org/10.32701/dp.22.1.4
}

\section{Introduction}

Wittgenstein's treatment of private language in his later work, Philosophical Investigations (PI), has probably received more attention than any other aspect of his philosophy. Here Wittgenstein argues against a private language. Nonetheless, in his earlier work, Tractatus Logico-Philosophicus, there are some remarks about the possible existence of private language. Although the issue of language is not a central topic of this book, it is very important to clarify a relation between the world and our representation of it, because world, thoughts and propositions share similar logical forms.

This paper will analyze a possible concept of private language argument in Tractatus Logico-Philosophicus (TLP), its interpretations, and Wittgenstein's own interpretation in his later work Philosophical Investigations. We will offer our own interpretation of private language conception in TLP and connect it to contemporary linguistics.

\section{Private Language Concept in Tractatus Logico- Philosophicus}

The following is the most relevant citation from TLP regarding the possibility of private language:

the world is my world, shows itself in the fact that the limits of the language (the language which only I understand) mean the limits of my world. (TLP 1922: 5.62)

* Marko Kardum, PhD., University of Zagreb, Faculty of Croatian Studies,

E-mail:mkardum@hrstud.hr

* * Ines Skelac, PhD., assistant professor, Faculty of Philosophy and Religious Studies University of Zagreb, E-mail: ines.skelac@ffrz.hr 
In short, the argument is as follows: the world is my world because only I have the perception of objects, relations, etc. in the way that I have. Every other person has different perception from mine. Everything in the world can be expressed by language (The proposition is a picture of reality. The proposition is a model of the reality as we think it is. TLP 1922: 4.01.). Therefore, as I have my own picture of reality, which I express by language, I have a language that only I can entirely understand.

This idea is probably brought from Schopenhauer's work, who also has a kind of private language argument. According to Schopenhauer, the world is my idea (Schopenhauer 2010), and language is used to describe our ideas. Namely, when we express something using language, we express our own view or mental concept, not an occurrence from the outside world. This Schopenhauer's concept is very close to the one of Ferdinand de Saussure, the father of contemporary linguistics, who introduces the bilateral linguistic sign. Every linguistic sign has two aspects which are inseparably connected: the sound sequence or signifier (the level of expression), and the concept or signified (the level of meaning).

It seems that Wittgenstein is not entirely aware of the 'signified' part of the linguistic sign, because in TLP he argues:

The name means the object. The object is its meaning. (TLP 1922 3.203)

According to this quote, a name is directly assigned to an object, and there is no indirect category of signified.

In TLP, Wittgenstein does not mention the term 'private language', but "my language" and 'language that only I can understand". It is not completely clear from TLP what exactly the private language for Wittgenstein would be or if TLP contains private language argument or not. Here are a few open questions and possibilities:

- Does it have the same vocabulary as general language, but meanings are different, because everyone has a different perception (my perception of a cat is somehow different from anybody else's perception of a cat)?

- Does private language represent the origin of a language change that will, or will not, affect general language?

- What is the relation between private language and general language? Is private language the only language, or do we have both private and general language? 


\section{Reaction on private language concept from TLP in Philosophical Investigations}

The most famous paragraph for the argument against private language in Philosophical Investigations (PI) is as follows:

Now, what about the language which describes my inner experiences and which only I myself can understand? How do I use words to stand for my sensations?As we ordinarily do? Then are my words for sensations tied up with my natural expressions of sensation? In that case my language is not a 'private' one. Someone else might understand it as well as I.-But suppose I didn't have any natural expression for the sensation, but only had the sensation? And now I simply associate names with sensations and use these names in descriptions. - (PI 2009 256.)

This argumentation can help us to better understand Wittgenstein's conception of 'the language that only I can understand' from TLP (1922 5.62). Although this argumentation goes the opposite way, the essential part is the sentence 'my words for sensations tied up with my natural expressions of sensations'. Someone else could understand it as well, but in TLP, Wittgenstein will say: 'in his own way'.

Although this is not a topic of this paper, we just want to point out that in PI, the example with a beetle in a box (PI 2009 293) seeks to show that an objective judgment of private notions is not possible. According to Wittgenstein, the private notion of pain is like a beetle in a box. We all own a box and looking at our box we claim to know what a beetle is and how it looks like. But the problem is that none of us have access to someone else's box, which means that we cannot be sure that we see the same beetle. After all, we cannot even verify if a beetle is in someone else's box at all. Thus Wittgenstein argues that if we construe the grammar of the expression of sensation on the model of 'object and designation' the object drops out of consideration as irrelevant (PI 2009 293) it has objective value only as an allusion to the general type.

\section{Analysis of private language concept in TLP}

Let us first see what we know about private language from TLP. Wittgenstein argued that the limits of my language mean the limits of my world (TLP 1922 5.6). For further analysis of private language concept, it is important to put the concept of language in a relation to the concept of world.

Further, Wittgenstein argues that the world (the only world for us) is our world:

That the world is my world, shows itself in the fact that the limits of the language (the language which only I understand) mean the limits of my world. (TLP 1922 5.62.) 
This leads us to solipsism, which Wittgenstein stated himself:

Here we see that solipsism strictly carried out coincides with pure realism. (TLP 1922 5.64.)

The concept of world is defined in the very beginning of TLP:

The world is the totality of facts, not of things. (TLP 1922 1.1.)

Therefore, language, and consequently, private language, belongs to the realm of facts. This is also clear from the last point in the TLP: Whereof one cannot speak, thereof one must be silent. (TLP 1922 7.)

Let us now discuss the status of language itself - do we have a general language, or the only possible language is the private language? To answer this question, it is necessary to elaborate what the concept of solipsism means to Wittgenstein. In TLP, it is not strictly defined. The most relevant point, 5.64, where we see that solipsism strictly carried out coincides with pure realism, is already mentioned. According to 5.64., it seems that nothing except what is included in our world is present in the world. In other words, everything that exists, exists only through the viewpoint of the subject. The subject's presence is the only thing that is real, and his viewpoint is the only way of grasping the world. Therefore, the world is only my world.

Consequently, private language, or a language that only I can understand, is also the only possible language. But does it mean that we cannot understand each other? Not exactly. To answer this question, let us first discuss the nature of the relation between language and logic and language and thought.

The propositions show the logical form of reality. (TLP 1922 4.1.2.1)

Therefore, everything that can be expressed, can be expressed following the rules of logic. This is something that is true for every subject. We can argue that our feeling of pain is private because no one can fully understand how we feel it, even though this feeling is something that is, to some extent, common to all people. In any way, no one can teach another person about the nominal meaning of feeling, because you must feel it yourself, and then you can use some of the available terms for describing this feeling. Understanding someone else's feeling will be possible only through direct experience of their feeling; however, such an experience is impossible. The example of feelings is the most understandable, but the same thing happens when a subject uses any other term for describing anything else. Each of us have our own experience, background, knowledge. This is also supported by Russell's claim that feelings and images of memory cannot be, even theoretically, felt and observed by someone from the outside. (Russell 1912).

Accordingly, the idea of a private language is that each individual word or statement concerning feeling has no practical, communicative, or social meaning, therefore being, in each individual case, an exclusive expression 
of a meaning understandable only to the speaker in the speaker's own, private way.

According to TLP, meaning can be derived only from a proposition:

Only the proposition has sense; only in the context of a proposition has a name meaning. (TLP 1922 3.3)

This is consistent with one of the most famous claims of the later Wittgenstein, that of the meaning as use (PI 2009).

The meaning of words can be learned just from their usage. The usage should be common because all subjects use the same set of words to categorize all appearances in their lives. But it does not imply that they use them exactly as we have already mentioned earlier in this paper, as for Wittgenstein, the proposition is a picture of reality, but such a model of reality as we think it is (TLP 1922 4.01).

In order to be able to communicate with each other, it is essential for us to have a consensus of ordinary meanings. I.e., our language community must have an agreement about replicating world phenomena to a language.

4.063 But to be able to say that a point is black or white, I must first know under what conditions a point is called white or black; in order to be able to say " $p$ " is true (or false) I must have determined under what conditions I call " $p$ " true, and thereby I determine the sense of the proposition.

The world we perceive is a kind of unclear matter. All we have is a limited number of names. Each of them is represented by one circle, and some of the circles are overlapping. Each circle has different aspects of meaning that are included, but each language user will use it in his own way, and only he will know what the same name means to him.

To conclude, the language is general, but each of us have our own way of using it and understanding it. Therefore, we cannot speak about the private language argument in TLP. TLP contains arguments for a kind of solipsism, which implies that every subject can use the language in his own way.

\section{Interpretations of private language in TLP}

The private language in TLP and other parts of it have several interpretative problems as there are many interpreters. The differences between several interpretations make the entire concept of every interpretation to be controversial.

To interpret this part, it is very important to be aware of possible Russell's influence on Wittgenstein's solipsism. According to Russell, the only possible knowledge is knowledge by acquaintance. Because of that, I can only know myself and objects immediately given to me in acquaintance. This implies that I can have no knowledge of other-selves (Russell 1912). 
Two remarkable interpreters of private language argument in TLP are Cora Diamond (2000) and David Pears (1987).

Diamond claims that:

The Tractatus provides us with arguments against the Russellian idea of someone else's private object, the beetle in Bismarck's box. It lets us see that any such beetle would have no role in language or thought, but it left unmolested the beetle in one's own box. Russell's conception of how we can think about things in the minds of others was subjected to a critique, but the Tractatus left unexamined a questionable conception of what it is for our words to be about things in our own minds. (Diamond 2000, p. 283)

Diamond emphasizes that a crucial feature of Wittgenstein's account of the construction of complex propositions from elementary propositions is this: if I am to understand a non-elementary proposition, then the elementary propositions that go into its construction must themselves be propositions that I understand: they must be made up of names that I understand or could understand.

I could understand a general proposition about toothaches. Nonetheless, I could not understand one of its instances, a singular proposition about Bismarck's toothache. On Wittgenstein's account, therefore, I cannot use general sentences to identify by description an object that Bismarck can name, and I cannot. So, private objects in others' minds can play no role in my language - by figuring in the truth conditions of my claims about others' sensations. If there is a private language argument in the Tractatus, it depends on the principle that one person cannot have names for other people's private sensations.

Nevertheless, we should distinguish the concept of naming from the concept of understanding. Although it is possible that we cannot understand other peoples' feelings, it does not mean (nor it is written in TLP) that we cannot name them.

In 4.002, Wittgenstein wrote:

Language disguises the thought; so that from the external form of the clothes one cannot infer the form of the thought they clothe, because the external form of the clothes is constructed with quite another object than to let the form of the body be recognized. The silent adjustments to understand colloquial language are enormously complicated.

Names are the same in one language, but this does not imply that particular language users use them in the same way. But, what is private here is the thought, and 'the only language that I understand' (TLP 1922 5.62) is connected to a way in which thoughts of an individual are represented in a language.

On the other hand, Pears (1987) argues that Wittgenstein's target is Russell's discussion of privacy and acquaintance and his discussion of the self. According to him, Wittgenstein's aim is to improve Russell's position. Pears 
writes that TLP 5.6 presents 'a development of a thesis put forward by Russell' to the effect that 'the limits of my language will be a function of the simple objects with which I have achieved acquaintance through all senses' (Pears 1987, p. 156). Nonetheless, Pears 5.6s mainly with respect to solipsism and Schopenhauer's influence (that subject is not in the world, he is a limit of the world). Still, he does not focus on the possibility of private language.

\section{Private language in contemporary linguistics}

As pointed out by Harris (2001, p. 118), 'linguistics is a term of no great antiquity'. Its emergence in nineteenth century, and then its development in twentieth century, was probably most affected by Ferdinand de Saussure and his Course of General Linguistics that was published posthumously in 1916. His Course is now generally considered to be a turning point in twentieth-century linguistics, to the extent that researching language in terms of linguistics at the same time meant being de Saussurean (Harris 2001, p. 118). His distinction between classical philology and language inquiry later proved to be the moment of establishing contemporary linguistics as a science and, although at first criticized, de Saussure's work soon became the focal point of language research.

De Saussure's main contribution can be divided into three parts (de Saussure 1916, p. 20, Harris 2001, p. 119):

1) describing all known languages and their history;

2) finding language universals and formulating general laws common to all linguistic phenomena and

3) defining linguistics itself.

Considering the subject of this paper, there is little to no reason to deal with 1) and 3), so the focus here will be kept on 2). Furthermore, there are strong reasons not to think that describing all languages and their histories can represent a job well done considering all possible problems in doing so; from no scientific interest in some of the known languages due to the number of their speakers to the fact that many languages simply disappear due to lack of speakers in the first place, just to name a few. Also, defining linguistics itself stands in no relation whatsoever to the language phenomena we are here dealing with. Although de Saussure anticipated Wittgenstein's view of linguistic semantics and his rejection of traditional nomenclature model which claims that words are simply attached to the things existing in the world (Harris 2001, p. 129), the main question regarding relation between de Saussure's and Wittgenstein's work is the one concerning language universals and general laws. The reason behind making this a main ques- 
tion is they can represent the linguistic ground for rejecting the notion of private language and establishing language as one structure that governs our thoughts and enables communication within a certain language community, even if solipsism, the way Wittgenstein thought of it, was true. For de Saussure, private and general language can basically be connected with one of his characteristic dichotomies, that of language as general and speech as individual.

Language, as a system of linguistic habits, as denoted by de Saussure, or as a system of life forms, as denoted by the late Wittgenstein, depicts the picture of the world. Everything we perceive in the world, every object, every person, every situation in our daily life, is reflected in language. Our use of language signs, our habit of using them, as well as the rules of their use, seem like a tangible way of finding our way of comprehending the world, especially communicating with others. Language seems necessary for us to communicate with others and it is our map for navigating the world.

Hence de Saussure derives the claim that we have no sovereignty over language, but that it is imposed on us, as it is, unaltered and preserved for generations of our history. The language always appears as a legacy from a previous period. In fact, no society knows and has never known language other than as a product inherited from past generations and which must be accepted as it is.

Language as a system of signs in a particular human community is not the same as language activity or human language in general (language as a human ability), but is only one part of it. Language activity can be defined as the human ability to communicate with voice signs, involving complex physical activity and assuming a symbolic function. Linguistic ability thus encompasses the totality of linguistic phenomena and individual languages, and in a particular community it manifests itself in two ways: language as a system of signs and speech as the application of that system in the act of communication. While people acquire language ability from nature, language is acquired in society and is conventional, and cannot be separated from speech. Language is an inventory of means (a system of vocabulary and grammatical signs) without which verbal communication is not possible, and as an abstract system of signs it potentially comes into the consciousness of an individual who is the speaker of a particular linguistic community. But language does not depend on the individual and no individual rules its totality. The language therefore belongs to the collective, it is possessed only by the mass of its speakers.

Speech is the individual application of language in the act of communication, or the individual realization of language. It involves numerous variations from individual to individual and from situation to situation, but must be realized according to the conventional rules of language as a system of 
signs. Language is a product of society that an individual passively receives, and speech is an individual and immediate realization of individual will and intelligence. But there is a kind of paradox about this, which can be posed in the form of the following question: how do speakers continue to use language effectively when it is constantly changing? That is, what is actually general and what is individual - language or speech?

But de Saussure senses this problem. Therefore, he also talks about the variability of the linguistic sign, while he reveals time as the main factor of variability. Although on the one hand time ensures the permanence of language, as de Saussure points out, it has another effect, which seems to contradict the former - it changes linguistic signs. So when we refer to language as a system of linguistic habits being imposed on us, we have to acknowledge both changes in an abstract system of signs and in speech as particular and individual usage. But maybe, due to total language activity being a social and therefore conventional thing, we are safe to assume that individual change in speech can be interpreted as confirmation of language as general activity we cannot evade if we are supposed to communicate with other individuals. Granted, contemporary linguistics does not have to assume anything like Wittgenstein's solipsism with its strong implications against the possibility of true understanding of other individuals' experiences of the world or our experiences of the world being truly understood by them. However, it will advocate constant language variations triggered by all sorts of different social and economic reasons (age, social class, ethnicity, etc.) that can manifest, again, in different language phenomena such as morphology, phonetics, syntax, semantics and pragmatics. Those variations can, but do not have to, lead to language changes while it is impossible not only to track but also to even claim that such language changes occur without different variations triggered by socio-economic conditions of speakers (Labov 1972). So how does it work? Contemporary linguistics, inspired by, so to say, de Saussure hinting the problem, confirmed two levels of language activity with regard to language change (Aitchison 2001, p. 95):

1) superficial level at which change is constant and that enables different languages to deal with possible novelties, different experiences of the world and different roles its users want to play in their communities, again, depending on their backgrounds. It is possible to imagine individuals wanting to sound more educated or more prestigious. At this level 'how changes occurred was closely linked to why" and speakers triggered it 'sometimes consciously, at other times without realizing it” (Aitchison 2001, p. 96). And

2) deeper level that is connected with general ability to communicate at which 'language maintains its patterns, and preserves efficient linguistic interaction” (Aitchison 2001, p. 96). 
It may seem that the former belongs to individual speech and that the latter applies to an abstract language sign system but while we now have superficial and deeper level of language changes, it is still unknown what is to be considered as general or individual, mostly due to both levels being common to individual speakers which, again, all fall into the same category of arbitrary sign communicators. This becomes even clearer when we realize that both levels can trigger language changes and that only some of those changes will actually occur: 'But although social desires and cultural needs may trigger change, the changes triggered are ready to happen at a deeper level. Only certain changes are likely to occur" (Aitchison 2001, p. 104). Therefore, we must conclude there is only one language which shows both its mental and social existence with former being the one we completely understand and the latter being the communication form that we all share and that is, in a way, being imposed on us just as the abstract arbitrary system of signs. That being said, this short analysis of language change in contemporary linguistics confirms there is no true distinction between private and general language.

It is often claimed that one of the most influential and most cited researchers in contemporary linguistics is Noam Chomsky (for interesting refutation of these claims that are even being referred to as a myth see Salkie 2001, pp. 105-106). With acknowledging different stages of his generative grammar concept, here his 'Standard theory" will be laid out and used to address the problem of private language existence. The reason behind including Chomsky's work is two-folded: 1) Chomsky's concept of generative grammar is closely connected with de Saussure's search for language universals and general laws that govern different natural languages and 2) Chomsky's real influence in linguistics is maybe far smaller than it is widely accepted but his work still represents what may be considered as crucial influence in contemporary linguistics. That being said, together with de Saussure, Chomsky can be considered as the one searching for language universals and the one having a major, maybe even decisive, influence on forming contemporary linguistics and defining its problems. As such, his work represents legitimate linguistic ground upon which it should be possible to analyze the possibility of supposed Wittgenstein's notion of private language.

While also dealing with 'technical" questions such as how any natural language is stored in the brain and how it is being used, which manifests in one's behavior, Chomsky's central analysis of language (1957) is mainly concerned with the system of language knowledge and its appearance in one's mind. Answering these two questions, namely how the system of language knowledge works and how language then appears in one's mind, is interconnected. Chomsky proposed the concept of generative grammar, that 
is, a formal system that enables construction of infinite number of different meanings and sentences using a finite number of words. But how is it accomplished? According to Chomsky, there are parts of our linguistic disposition that are innate or genetically built in and hardwired. As such, we must consider them being generally applicable to any natural language and sufficient proof of such claim should be the fact that we are not predisposed to learn any particular language. On the contrary, there is a portion of grammar rules common to each potential language user. Consequently, language can either exist in the brain at birth via genes, or can be developed in the brain also via genes (Salkie 2001, p. 111). Of course, language acquisition in terms of acquiring words of particular natural language has nothing to do with biology, genes and innate structures, it is by no means nothing more than experience randomly generated by multiple factors such as geographical position, social class, education, etc. According to Chomsky's explanation, there is empirical evidence of different human endeavors that show plausibility of innate structures. Take for example the way humans learn to walk - there is empirically grounded order of rules followed by appropriate age of individuals - one is only at some point able to take certain locomotory actions and that is exactly when one will actually strive to master them. With some degenerative cases taken into account, this will appear regularly across entire human population and, as such, it pinpoints biological origin of instructions essential for walking. As with walking, language activity follows the same rules and order, certain language activities will be developed at correlated age and with correlated brain abilities. That in turn means language activity is also biologically determined and innate and therefore we must abandon empirical approach when asking where the language comes from. In terms of particular words and meanings, it is fine to keep empirical approach and focus on individual language acquisition. At this point, when it comes to dichotomy of private and general language existence it maybe becomes more obvious what we should consider to be universal structure and what falls down to individual properties of language. However, generative grammar concept tells us there is a general language structure under which all natural languages must fall and that exactly is the case with finite possibilities of constructing sentences that make sense. Natural language word acquisition depends on individual and contingent circumstances and, by being such, it allows infinite number of different word combinations. It may be the case that this is what gives linguistic foundation to Wittgenstein's understanding of language as use and what may stand behind his pragmatic view of language characteristic for PI which replaced the one of logical atomism characteristic for TLP. But in regard to what has been said earlier, this does not bring us any closer to thinking that contemporary linguistics approves of private language concept such as the one that, according to some 
of his commentators, could follow from Wittgenstein's understanding of language. There is nothing here that obliges us to the notion of private language instead of aforementioned solipsism - it is still the case that language is understood as a general structure under which all of individual use fall. By having private experiences, we are still left short of comprehending those experiences themselves together with complete understanding of language used to describe and explain the world in terms of our experience. What was pointed out here, both in the case of de Saussure and Chomsky, is that there is only one language that is universal in its structure and that is formed in a way that allows us communication.

\section{Conclusion}

In this paper, we aimed to show that there is no private language argument in TLP. What is present there is that, because of solipsism, we use general language as a tool for expressing our own way of world capturing. This is the reason why nobody else can understand our language, as nobody else has the same way of seeing the world as we have. Nonetheless, we can communicate with other people because all of us (in our language community) use language as a frame in which all of us must fit in.

Further, there is no distinction between private and general language because the only language that we understand is also the only language for us. This is also noticeable in a paradox that comes from de Saussure's dichotomy of language and speech, as the question is what is individual, and what is common.

By analyzing de Saussure's and Chomsky's approach connected to the topic of private language, we concluded that there is no room for private language, just for a general language with a structure that allows communication in a language community. That seems to be very close to Wittgenstein's idea expressed in TLP, especially with regard to his view of relation between language, logic and our thoughts - propositions show the logical structure of reality, both of which we cannot abide. Only in a context a name has a meaning which brings us just a step closer to language pragmatics to which he turned to in PI.

\section{References}

Aitchison, J. (2001). Language Change, in Cobley, P. Routledge Companion to Semiotics and Linguistics (London: Routledge) pp 95-104

Diamond, C. (2000). Does Bismarck Have A Beetle In His Box?: The Private Language Argument in the Tractatus, in Crary, A. \& Read, R. (eds.) The New Wittgenstein (London: Routledge) pp. 272-302 
Harris, R. (2001). Linguistics after Saussure in Cobley, P. Routledge Companion to Semiotics and Linguistics (London: Routledge) pp 118-133

Hessell, C. (2018). Solipsism and the Self in Wittgenstein's Tractatus, Journal of the History of Philosophy, 56(1), pp. 127-154

Labov, W. (1972). Sociolinguistic Patterns ( Philadelphia PA: University of Pennsylvania Press)

Chomsky, N. (1957). Syntactic Structures (The Hague: Mouton)

Pears, D. (1987). The False Prison, Vol. I (Oxford: Clarendon Press)

Russell, B. (1912). The Problems of Philosophy (New York: H. Holt and Company) Project Gutenberg https://www.gutenberg.org/files/5827/5827-h/5827-h.htm

Salkie, S. (2001). The Chomskian Revolutions, in Cobley, P. Routledge Companion to Semiotics and Linguistics (London: Routledge) pp 105-117

Schopenhauer, A. (2010). The World as Will and Representation, Vol. I, translated by J. Norman, A. Welchman, and Ch. Janaway (Cambridge: Cambridge University Press)

Wittgenstein, L. (1922). Tractatus Logico-Philosophicus, translated by C. K. Ogden (New York: Harcourt, Brace \& Company, Inc.) Project Gutenberg https://www. gutenberg.org/files/5740/5740-pdf.pdf (TLP)

— (2009). Philosophical Investigations (Oxford: Wiley-Blackwell) (PI)

Abstract

\section{NOTION OF PRIVATE LANGUAGE IN WITTGENSTEIN'S TRACTATUS LOGICO-PHILOSOPHICUS AND SOME CONTEMPORARY LINGUISTIC REFUTATIONS}

\section{MARKO KARDUM, INES SKELAC}

In this paper, the possibility of private language argument in Tractatus Logico-Philosophicus is analyzed. The concept of "language that only I could understand" is connected to solipsism, or the impossibility to understand other people's way of seeing the world. But all members of the same community are able to communicate using the same language, so this language is a general language, and there is no private language, just a private perception of the world. Contemporary linguistic theories of Chomsky and de Saussure are close to this interpretation of private language.

KEY wORDS: Chomsky, general language, private language, de Saussure, solipsism, Tractatus Logico-Philosophicus, Wittgenstein 